\title{
A genomic view of the peopling of the Americas
}

\author{
Pontus Skoglund ${ }^{1,2,3}$ \& David Reich ${ }^{1,2,4}$ \\ ${ }^{1}$ Harvard Medical School, Boston, MA, USA \\ ${ }^{2}$ Broad Institute of MIT and Harvard, Cambridge, MA, USA \\ ${ }^{3}$ Department of Archaeology and Classical History, Stockholm, Sweden \\ ${ }^{4}$ Howard Hughes Medical Institute, Boston, MA, USA
}

Whole-genome studies have documented that most Native American ancestry stems from a single population that diversified within the continent more than twelve thousand years ago. However, this shared ancestry hides a more complex history whereby at least four distinct streams of Eurasian migration have contributed to present-day and prehistoric Native American populations. Whole genome studies enhanced by technological breakthroughs in ancient DNA now provide evidence of a sequence of events involving initial migrations from a structured Northeast Asian source population with differential relatedness to present-day Australasian populations, followed by a divergence into northern and southern Native American lineages. During the Holocene, new migrations from Asia introduced the Saqqaq/Dorset Paleoeskimo population to the North American Arctic $\sim 4,500$ years ago, ancestry that is potentially connected with ancestry found in Athabaskan-speakers today. This was then followed by a major new population turnover in the high Arctic involving Thule-related peoples who are the ancestors of present-day Inuit. We highlight several open questions that could be addressed through future genomic research.

\section{Introduction}

The peopling of the Americas represented the culmination of a Late Pleistocene expansion of anatomically modern humans out of Africa. Archaeological evidence indicates that groups subsisting on hunting lived in extreme northeast Siberia $\left(71^{\circ} \mathrm{N}\right)$ by at least 28,000 years ago [1]. Human groups adapted to the mammoth steppe habitat were thus poised to enter Beringia - the landmass between Alaska and Eurasia that is now submerged - by this time [2,3]. The path from Beringia to the more temperate parts of the American continents, however, was blocked by the merged Laurentide and Cordilleran ice sheets that covered northern North America until the end of the Last Glacial Maximum. The ice retreated from parts of the Pacific coast $~ 16,000$ years 
ago, raising the possibility of a coastal migration after this time, and within a few thousand years

36 a habitable corridor through the center of the continent opened between the two ice sheets [4].

37 The first unambiguous evidence of modern humans in the Americas dates to between 14,000 and 15,000 years ago [5-8], and was likely the consequence of migration from Beringia.

Major debates about the peopling of the Americas have focused on the question of whether the

41 first early human populations in the Americas are directly ancestral to present-day Native

42 Americans, as well as on the number, mode, and timing of secondary migrations to the

43 Americas. Advances in genomics have, within the last five years, enabled the collection of far

44 more data from present-day Native Americans than was available previously, and have also

45 made it possible for the first time to access DNA from ancient Native American remains.

46 Analysis of these data has highlighted a minimum of four distinct streams of Asian ancestry

47 some of which were not clear from the archaeological evidence. We review the contributions of

48 genomic data to understanding the prehistory of the Americas, and outline outstanding questions

49 where it may be able to provide additional insight.

\section{The power of the whole genome}

52 The first meaningful genetic insights about Native American population history came from 53 mitochondrial DNA, a segment of about 16,500 base pairs (approximately $1 / 200,000^{\text {th }}$ of the 54 genome) that is passed exclusively along the maternal line. Mitochondrial DNA was one of the 55 first parts of the genome to be heavily investigated to learn about human population history for 56 several reasons. First, it is highly variable on a per-nucleotide level and thus sequencing only a 57 short stretch can detect non-trivial amounts of human variation. Mitochondrial DNA's high 58 variability and short length meant that it was practical to sequence in large numbers of samples at 59 a time when it was prohibitively expensive to generate genome scale data. For ancient DNA 60 studies, mitochondrial DNA had the further advantage that it exists in about a thousand-fold 61 higher copy number than any other single place in the genome. Since one of the main challenges 62 of ancient DNA is obtaining sufficient amount of material from any position in the genome to be 63 able to analyze, beginning with more starting material can be an advantage [9]. 
65 The greatest contribution of mitochondrial DNA studies to the understanding of Native 66 American prehistory has been in the area of reconstruction of population size history. 67 Mitochondrial DNA analyses were the first to document that the ancestry of most Native 68 Americans derives from a population that experienced a profound founder event [10], with a 69 relatively small number of individuals giving rise to a large number of descendants today. The 70 evidence for this is that all Native American mitochondrial DNA lineages today descend from 71 just five founding maternal lines [11-13] that each had a common ancestor around 18,000 to 72 15,000 years ago, implying a population size bottleneck around this time [14-18]. The evidence

73 for a profound population bottleneck has since been confirmed and its intensity measured more 74 accurately with genome scale data [19-23], but it is important to note that there are still 75 challenges with disentangling the number of founder individuals from the duration of the 76 population size reduction using all the reported methods.

A second finding about Native American population history based on mitochondrial DNA data is that the founder event may have been proceeded by an extended period (many thousands of

81 This suggested to some researchers the hypothesis of a 'Beringian standstill', whereby the first 82 founding population of the Americas was isolated from Eurasian populations prior to its radiation into a multitude of sub-populations in America [15].

At the same time, some observations from mitochondrial DNA studies of the Americas have been more confusing than helpful. For example, the mitochondrial DNA subtype called D4h3a is today almost entirely restricted to Pacific coastal populations, both in North and South America.

88 This observation led to the hypothesis that D4h3a was carried by the members of a population 89 that carried Native Americans south of the ice sheets along a coastal route, in a migratory 90 movement that was distinctive from what led to many other Native American populations [24].

91 However, ancient DNA studies have since found the same mitochondrial DNA type in a 12,600 92 year old individual from present-day Montana, which based on its genome-wide data is 93 unambiguously from the main ancestral lineage leading to most Native Americans [25]. 
95 It is now clear that so many founder events and fluctuations in population size have occurred 96 before, during, and after the peopling of the Americas that the evidence from one position in the 97 genome-mitochondrial DNA, the $\mathrm{Y}$ chromosome, or any other location-is too subject to random changes in frequency (genetic drift) to be meaningful by itself. Only by taking the 99 independent testimony of many locations in the genome simultaneously can we obtain a highresolution picture of the deep past. The remainder of this article focuses on insights from whole genome studies about Native American history. While these studies are still in their early days,

102 they have already upended our understanding of key events in Native American population history. Application of ancient DNA technology promises further insights in years to come.

\section{Sources of Native American ancestry}

Under the hypothesis where Native American ancestry stems from a single founder population that separated earlier from Eurasian populations, differences in allele frequencies between Native American groups should have developed independently from Eurasian allele frequencies. This simple null hypothesis makes it possible to explicitly test hypotheses about the number of American founder populations. Reich et al. [23] applied this idea to the first comprehensive genome-wide data from Native American populations (52 populations, but none from the continental United States), and concluded that at least three ancestral populations-or streams of gene flow-were required to explain the similarities between Native Americans and East Asians. According to the initial study [23], all Native American groups from Central and South America

115 fit a model of a single founder population. An additional source of ancestry was necessary to explain genetic variation in Eskimo-Aleut speakers. In addition, analysis of the Athabaskan-

117 speaking Chipewyan revealed that they could not solely have their ancestry from the same

118 founding population as other Northern-, Meso- and South American populations.

\section{The main ancestral stream giving rise to Native American ancestry}

121 One of the most important pieces of genetic evidence relevant to the peopling of the Americas was the sequencing of a genome from the remains of a child ('Anzick-1') buried with Clovis 123 artifacts in western Montana and directly dated to 12,600 before present (BP) [25]. This child 124 was consistent with deriving all of his ancestry from the same founding population as Central 125 and South Americans (Figure 1), contradicting the 'Solutrean hypothesis' of transatlantic 
migration from Upper Paleolithic Europe giving rise to the Clovis industry [26] which thus posits

127 genetic discontinuity between the makers of the Clovis industry and present-day Native Americans [27]. The most surprising finding was that the Anzick individual is from a population more closely related to Central- and South Americans than to some northern North Americans

130 (including all speakers of Algonquian languages studied to date), despite the apparent common ancestral origin of Native Americans across the continents. This suggests that the present-day population structure of the main ancestry in Native Americans [23] dates back to more than 12,600 years ago [25], and that this diversification divided the ancestry of present-day Native Americans into two main streams, one of which includes the ancestors of present-day Northern Native Americans analyzed ('NNA': Cree, Ojibwa, and Algonquin), and the other of which includes the Anzick individual and present-day Central- and South American groups ('SA': e.g. Mixe, Quechua, and Yaghan).

While we thus have evidence for SA ancestry in the Late Pleistocene in the form of the Anzick genome, an outstanding question is where the ancestors of NNA were localized. One possibility is that they were confined to ice-free regions north of the corridor between the Cordilleran and

142 Laurentide ice sheets, and only expanded south after 12,600 BP, where this ancestry would 143 eventually displace the SA populations represented by Anzick (Figure 2). Another possibility might be an expansion of the Clovis industry from a southern origin that also represented a population expansion by SA populations into regions where NNA populations were located (Figure 2). Thus SA populations might have brought Clovis technology to some regions in

More recent genome sequencing [28] of the 9,000 year-old Kennewick individual ('the Ancient One') did not provide resolution about this issue. While the genome analysis showed that the Kennewick individual had the great majority of its ancestry from the same deep source as other present-day Native Americans, his affinity to the SA and NNA lineages remains ambiguous.

155 Until 2014, efforts to infer demographic parameters for the peopling of the New World based on genetic data focused on modeling Native Americans as an offshoot of East Asian ancestry 
157 [17,20,23,29-34]. However, the analysis of the genome of a 24,000 year-old individual from the 158 Mal'ta site near Lake Baikal in Central Siberia revealed that this model is untenable. The Mal'ta individual shared genetic affinities to both European (West Eurasian) and Native American populations [35]. Analyses showed that a scenario in which Mal’ta descended from an admixture

161 between a West Eurasian population and an ancient population that was also ancestral to Native Americans could not explain all features of the data [35]. However, the data was consistent with a model in which Native Americans are admixed between lineages related to Mal'ta on the one hand (between $1 / 4$ and $1 / 2$ of Native American ancestry) and East Asians on the other hand (Figure 1). Thus, Native Americans and East Asians do not in fact descend from a common ancestral population that separated earlier from a lineage leading to Mal'ta and to West Eurasians [35].

The finding of ancient mixture in the ancestry of Native American-prior to diversification within the Americas-also has consequences for modeling other features of Native American population history. Genetic debate about the date of the first migrants into the Americas has had,

171 as one of its important themes, estimation of the date of genetic divergence of the lineages giving 172 rise to Native American and East Asian populations [31]. The major admixture related to the 173 Mal'ta lineage in the ancestry of all Native Americans is inconsistent with the assumption of a 174 simple population split between Native Americans and East Asians that has been the basis for the most attempts to date to infer the population split times, and which have suggested dates of around 23,000 years ago [33,34]. The substantial contribution of the Mal'ta lineage to Native

177 Americans may have the effect of upwardly biasing estimates of the time of divergence of Native 178 Americans and East Asians. Future models estimating parameters for the founding populations of the Americas will need to consider this admixture explicitly.

\section{An Australasian Connection}

182 Recently, we carried out a stringent test of the null hypothesis of a single founding population of 183 Central and South Americans using genome-wide data from diverse Native Americans [36]. We detected a statistically clear signal linking Native Americans in the Amazonian region of Brazil to present-day Australo-Melanesians and Andaman Islanders ('Australasians’). Specifically, we

186 found that Australasians share significantly more genetic variants with some Amazonian 187 populations-including ones speaking Tupi languages-than they do with other Native 
Americans. We called this putative ancient Native American lineage "Population Y" after Ypykuéra, which means 'ancestor' in the Tupi language family.

To learn more about the Population Y ancestry present in the Americas, we carried out a series of 192 statistical modeling analyses. We found that the patterns of genomic variation of present-day Amazonians could be explained by as little as 2\% admixture from an Australasian-related population, that would thus have penetrated deep inside the Americas without mixing with the main ancestral lineage of present-day Native Americans. Alternatively, the patterns could be explained by a larger proportion of ancestry (2-85\%) from a population that existed in a substructured Northeast Asia, and was similar to the main lineage that gave rise to other Native Americans while retaining more Australasian affinity.

We considered the possibility that these genetic patterns relate to the claims based on skeletal morphology that there was an wave of migration related to Australasians that contributed to early Native Americans, followed by later large-scale population replacement by the primary ancestors of present-day Native Americans [37,38]. While this evidence has been contested on morphological grounds-with the most important critique being that the analyses are not statistically compelling [2,39]— the fact that the morphological evidence is strongest in Brazil where Population $\mathrm{Y}$ ancestry is prevalent justifies investigation into possible connections. However, new genetic findings reject one set of the arguments based on morphology: that the morphology of groups such as historic-period Native Americans in the Baja California region of Mexico and the Tierra del Fuego region in the southern tip of South America suggests that they are related to the hypothesized earlier Australasian-related migration. Genomic DNA from these

What is the history behind the Population $\mathrm{Y}$ ancestry in Amazonian Native Americans today?

214 Little can be said at present, as we do not have ancient DNA from individuals carrying detectable amounts of this ancestry. The implication that the Siberian populations that gave rise to the ancestors of Native Americans was substructured, however, is not surprising given that the

217 24,000-18,000 years from the Lake Baikal region of Siberia (the Mal'ta and Afontova Gora sites) 
suggest that a population that has not yet been sampled with ancient DNA data-one with more Australasian-related ancestry-may also have been present in the broad geographic area to contribute to the founders of Native American founders. Notably, Andaman Islanders, the population with the single strongest affinity to Amazonians, are not as good match for the nonMal'ta like ancestry in Central Americans as are Chinese populations [36]. These strands of evidence suggest a minimum three-part ancestry of the Beringian populations that came to populate the Americas (Figure 1). Two of these strands were fully braided together to form the main ancestral lineage of Native Americans by the time of the Beringian bottleneck. However, the third strand, with an affinity to Australasians, was not.

It has been suggested that Native American ancestors may have entered the more temperate parts of North American both by an early coastal route and the later ice free corridor [2]. One possibility is that the different sources of deep ancestry that are inferred by these genetic patterns may reflect movements of a substructured Beringian population through these different routes. Alternatively, the patterns could reflect pulses of migration from Beringia occurring at different times (e.g. multiple pulses through the ice free corridor). Restricting study to South America, a related question is the history behind the deeply structured population lineages East and West of the Andes in South America that have been documented based on genomic data [23]. Population Y ancestry may be limited entirely to the eastern populations, raising the possibility that this split was extremely ancient.

\section{Post-glacial migrations into North America}

241 The archaeological record of the North American Arctic documents a transformation beginning 242 around a thousand years ago and associated with the Thule cultural complex. The Thule culture advanced into a North American Arctic occupied by the descendants of previous migrations,

244 referred to as Paleoeskimos and culturally represented by the Saqqaq and Dorset technological 245 complexes [41]. Genome-wide data from a 4,000 year old Saqqaq culture individual in 246 Greenland - the first genome-wide dataset from an ancient human-was interpreted as showing 247 that the Saqqaq population went extinct in North America, since the Saqqaq genome was most 248 similar to present-day Koryak and Chukchi on the eastern side of the Bering strait in clustering analyses [42]. Genome-wide analysis of additional samples from the Early Dorset and Middle 
250 Dorset cultures - along with Thule individuals - confirmed the picture of distinct ancestry in 251 Paleoeskimos, and a population break associated with the Thule that led directly to present-day 252 Inuit populations [43].

254 A major outstanding issue in the interpretation of the peopling of the Arctic relates to the geographic and temporal origins of the distinct Asian ancestry present in speakers of Athabaskan (Na-Dene) languages [23,43,44]. Two distinct models for Paleoeskimo and Athabaskan-speaking ancestry have been proposed based on the genetic data. Raghavan et al. [43] proposed that Athabaskan speakers do not harbor ancestry from Paleoeskimos; instead, they suggest that the east Asian affinities in the Athabaskans may be due to admixture with Inuit (Neo-Eskimos). Reich et al. [23] reported a statistical test that significantly rejects this hypothesis: they showed that ancestry in Athabaskan speakers cannot be modeled as a mixture of the lineages that have given rise to other Native American and Inuit population living today. However, a model in which Athabaskan-speakers harbor about $10 \%$ of their ancestry from a source that is distinct

264 from both the Inuit and the main ancestry in other Native Americans-possibly related to the Saqqaq Paleoeskimo - may be consistent with the data [23]. However, several of these inferences may be complicated if Siberian populations today have substantial amounts of ancestry from back-migrations out of America. An important direction for future research is to determine the origin of the distinct Asian ancestry present in Athabaskans using higher resolution methods and additional data.

\section{Prospects}

272 Far more remains to learn about the genomic history of Native Americans than has already been 273 discovered. Major directions for future data collection include more ancient DNA data, and 274 filling in sampling gaps of present-day Native American populations, especially in United States. 275 We conclude by highlighting five major open questions about Native American population 276 history that we believe may be meaningfully addressed using genomic data in the coming years.

278 (1) What is the origin of Population Y in Amazonia - can we find it in ancient DNA? 
280 (2) What is the origin of the lineage found in many present-day northern North Americans but not in the 12,600 year old Anzick genome?

(3) What is the history of peopling and migration in South America? Was there an early population split east + and west of the Andres, and how much major migration occurred after the first people arrived?

(4) What is the genetic legacy of the Paleoeskimos? Can this widespread population really have disappeared completely after the arrival of the Thule and Aleuts or have they left some descendants, perhaps in admixed form in Athabaskan speakers?

(5) What was the structure of Native American populations in North America prior to the disruption of the last 500 years?

294 We conclude by emphasizing that true understanding of the population history of any group or 295 region cannot be achieved through genomic studies alone, but requires a synthesis of insights 296 from genomics with information from anthropology, linguistics, archaeology, and sociology. It 297 will also be important to involve Native American organizations and communities in dialogues 298 about these studies, as their perspectives have been underrepresented in these studies in the past.

\section{Acknowledgements}

301 We thank Lars Fehren-Schmitz, David Meltzer and Jennifer Raff for critical comments. P.S. was 302 supported by the Wenner-Gren foundation and the Swedish Research Council (VR grant 2014303 453). D.R. was supported by NIH grant GM100233, by NSF HOMINID BCS-1032255, and is a 304 Howard Hughes Medical Institute investigator. 
Figure 1. Eurasian source populations of the earliest Native Americans. A) Diverse population lineages that genetic evidence suggest were present in Northeast Asia and contributed to the ancestry of present-day Native Americans. These comprise people with ancestry related to present-day Andamanese and Australo-Melanesians (red), people related to present-day East Asians such as Han Chinese (pink), and people related to the 24,000 year old Mal'ta child buried near Lake Baikal (dark blue). By 12,600 years ago, at least the Mal'ta-related and east Asianrelated ancestries were already present in the proportions found in Native Americans today in the Anzick child from Western Montana (B). Today, the Andamanese-related ancestry can be detected as an excess affinity to present-day Amazonians (B).

Figure 2. Two scenarios explaining that the 12,600 year old Anzick individual is more closely related to South and Central-Americans than Northern Native Americans. A) Clovis technology appears first in the southern parts of North America. It is thus possible that Anzick, being associated with Clovis artifacts and dating to the end of the Clovis period, represents a northwards expansion into a region where the ancestors of present-day northern Native Americans were already established. B) An alternative is that the southern lineage associated with the Anzick individual represents the first migration south of the ice sheets, whereas the ancestors of present-day Northern Native Americans resided north of the ice sheets at 12,600 years ago and only later migrated southwards, replacing the Anzick-like population. C) Both these scenarios could explain the observation that Anzick is more closely related to Southern Native American populations.

Figure 3. Holocene migrations to the Americas. There is a current consensus supporting a Paleoeskimo migration to Greenland 4,500 years ago, giving rise to both the Saqqaq culture and the Early, Middle and Late Dorset cultures. This Paleoeskimo population was displaced by NeoEskimos associated with the Thule culture migrating through the Arctic 1,000 years ago, although there remains a possibility of some admixture. Two scenarios can plausibly explain the Asian ancestry flow in present-day speakers of Athabaskan (Na-Dene) languages. 1) The NaDene have ancestry from a distinct migration to the Americas from that seen in any other ancient samples. 2) The Na-Dene-specific ancestry comes from the same migration as the Paleoeskimos [23]. A proposed model in which the Na-Dene-specific ancestry is from the same migration that contributed to the Inuit [34] has been rejected statistically [23]. Note that these arrows are not intended to show exact geographic migration routes. 


\section{References}

**outstanding interest

Rasmussen et al. 2014. This paper presents the oldest genome-wide data from the Americas reported to date, documenting the presence of the main source of ancestry in present-day Native

Northern and Southern groups persisting since the Late Pleistocene until today.

Raghavan et al. 2014, This paper reports the draft genome sequence of a 24,000 year old individual from Central Siberia, showing that Native Americans are not just a branch of East Asian lineages, but are an admixture of sources related to East and West Eurasians.

Reich et al. 2012. This paper reports the first comprehensive genome-wide data set of Native Americans. Analysis of these data documented evidence for at least three streams of ancestry into the Americas: the lineage giving risk to most Native American ancestry, one giving rise to the Inuit, and one that contributed some of the ancestry of present-day Athabaskan-speakers.

Skoglund et al. 2015. This paper provides evidence of ancestry related to Australo-Melanesians and Andaman Islanders in present-day populations of Amazonia, documenting a previously unknown stream of migration into the Americas.

*special interest

Rasmussen et al. 2010. This paper presented the first ancient human genome, from a $\sim, 000$ year old Saqqaq Paleo-Eskimo, and showed that most of its ancestry derived from a migration from Asia distinct from the one that gave rise to most of the ancestry of present-day Native American and Inuit populations.

Raghavan et al. 2014. This paper presents low-coverage genomic sequence data from NeoEskimos and Paleo-Eskimos, providing support for the hypothesis these two cultural groups were biologically distinct, and that Neo-Eskimos are the ancestors of present-day Inuit.

Raghavan et al. 2015. This paper analyzed genome-wide data from historical Pericu and Fuegians, and rejected hypotheses based on morphology that these populations carried ancestry radically different from present-day Native Americans. 
379

380

381

382

383

384

385

386

387

388

389

390

391

392

393

394

395

396

397

398

399

400

401

402

403

404

405

406

407

408

409

410

411

412

413

414

415

416

417

418

419

420

421

422

423

424

425

426

427

428

1. Pitulko V, Nikolsky P, Girya E, Basilyan A, Tumskoy V, Koulakov S, Astakhov S, Pavlova E, Anisimov M: The Yana RHS site: humans in the Arctic before the last glacial maximum. Science 2004, 303:52 - 56.

2. Meltzer DJ: First peoples in a new world: colonizing ice age America: Univ of California Press; 2009.

3. Goebel T, Waters MR, O'Rourke DH: The late Pleistocene dispersal of modern humans in the Americas. science 2008, 319:1497-1502.

4. Heintzman PD, Froese D, Ives JW, Soares AER, Zazula GD, Letts B, Andrews TD, Driver JC, Hall E, Hare PG, et al.: Bison phylogeography constrains dispersal and viability of the Ice Free Corridor in western Canada. Proceedings of the National Academy of Sciences 2016.

5. Gilbert MTP, Jenkins DL, Gotherstrom A, Naveran N, Sanchez JJ, Hofreiter M, Thomsen PF, Binladen J, Higham TFG, Yohe RM, et al.: DNA from pre-Clovis human coprolites in Oregon, North America. Science 2008, 320:786-789.

6. Dillehay TD, Ramirez C, Pino M, Collins M, Rossen J, Pino-Navarro J: Monte Verde: seaweed, food, medicine, and the peopling of South America. Science 2008, 320:784-786.

7. Waters MR, Stafford TW, McDonald HG, Gustafson C, Rasmussen M, Cappellini E, Olsen JV, Szklarczyk D, Jensen LJ, Gilbert MTP, et al.: Pre-Clovis Mastodon Hunting 13,800 Years Ago at the Manis Site, Washington. Science 2011, 334:351-353.

8. Jenkins DL, Davis LG, Stafford TW, Campos PF, Hockett B, Jones GT, Cummings LS, Yost C, Connolly TJ, Yohe RM, et al.: Clovis Age Western Stemmed Projectile Points and Human Coprolites at the Paisley Caves. Science 2012, 337:223-228.

9. Pääbo S: Ancient DNA; extraction, characterizaation, molecular cloning and enzymatic amplification. Proceedings of the National Academy of Sciences 1989, 86.

10. Wallace DC, Garrison K, Knowler WC: Dramatic founder effects in Amerindian mitochondrial DNAs. American Journal of Physical Anthropology 1985, 68:149-155.

11. Torroni A, Schurr TG, Yang C-C, Szathmary EJ, Williams RC, Schanfield MS, Troup GA, Knowler WC, Lawrence DN, Weiss KM: Native American mitochondrial DNA analysis indicates that the Amerind and the Nadene populations were founded by two independent migrations. Genetics 1992, 130:153-162.

12. Horai S, Kondo R, Nakagawa-Hattori Y, Hayashi S, Sonoda S, Tajima K: Peopling of the Americas, founded by four major lineages of mitochondrial DNA. Molecular Biology and Evolution 1993, 10:23-47.

13. Torroni A, Schurr TG, Cabell MF, Brown MD, Neel JV, Larsen M, Smith DG, Vullo CM, Wallace DC: Asian affinities and continental radiation of the four founding Native American mtDNAs. American journal of human genetics 1993, 53:563.

14. Mulligan CJ, Kitchen A, Miyamoto MM: Updated Three-Stage Model for the Peopling of the Americas. PLOS ONE 2008, 3:e3199.

15. Tamm E, Kivisild T, Reidla M, Metspalu M, Smith D, Mulligan C, Bravi C, Rickards O, Martinez-Labarga C, Khusnutdinova E, et al.: Beringian standstill and spread of Native American founders. PLOS One 2007, 2:e829.

16. Llamas B, Fehren-Schmitz L, Valverde G, Soubrier J, Mallick S, Rohland N, Nordenfelt S, Valdiosera C, Richards SM, Rohrlach A, et al.: Ancient mitochondrial DNA provides high-resolution time scale of the peopling of the Americas. Science Advances 2016, 2.

17. Hey J: On the Number of New World Founders: A Population Genetic Portrait of the Peopling of the Americas. PLOS Biol 2005, 3:e193.

18. Tackney JC, Potter BA, Raff J, Powers M, Watkins WS, Warner D, Reuther JD, Irish JD, O'Rourke DH: Two contemporaneous mitogenomes from terminal Pleistocene 
burials in eastern Beringia. Proceedings of the National Academy of Sciences 2015, 112:13833-13838.

19. Ramachandran S, Deshpande O, Roseman CC, Rosenberg NA, Feldman MW, CavalliSforza LL: Support from the relationship of genetic and geographic distance in human populations for a serial founder effect originating in Africa. Proceedings of the National Academy of Sciences of the United States of America 2005, 102:1594215947.

20. Wang S, Lewis CM, Jr., Jakobsson M, Ramachandran S, Ray N, Bedoya G, Rojas W, Parra MV, Molina JA, Gallo C, et al.: Genetic Variation and Population Structure in Native Americans. PLoS Genet 2007, 3:e185.

21. Jakobsson M, Scholz SW, Scheet P, Gibbs JR, VanLiere JM, Fung H-C, Szpiech ZA, Degnan JH, Wang K, Guerreiro R: Genotype, haplotype and copy-number variation in worldwide human populations. Nature 2008, 451:998-1003.

22. Li JZ, Absher DM, Tang H, Southwick AM, Casto AM, Ramachandran S, Cann HM, Barsh GS, Feldman M, Cavalli-Sforza LL, et al.: Worldwide Human Relationships Inferred from Genome-Wide Patterns of Variation. Science 2008, 319:1100-1104.

23. Reich D, Patterson N, Campbell D, Tandon A, Mazieres S, Ray N, Parra M, Rojas W, Duque C, Mesa N, et al.: Reconstructing Native American population history. Nature 2012, 488:370 - 374.

24. Perego UA, Achilli A, Angerhofer N, Accetturo M, Pala M, Olivieri A, Kashani BH, Ritchie $\mathrm{KH}$, Scozzari R, Kong Q-P, et al.: Distinctive Paleo-Indian Migration Routes from Beringia Marked by Two Rare mtDNA Haplogroups. Current Biology 2009, 19:1-8.

25. Rasmussen M, Anzick SL, Waters MR, Skoglund P, DeGiorgio M, Stafford Jr TW, Rasmussen S, Moltke I, Albrechtsen A, Doyle SM, et al.: The genome of a Late Pleistocene human from a Clovis burial site in western Montana. Nature 2014, 506:225-229.

26. Bradley B, Stanford D: The North Atlantic ice-edge corridor: A possible Palaeolithic route to the New World. World Archaeology 2004, 36:459-478.

27. Raff JA, Bolnick DA: Does Mitochondrial Haplogroup $X$ Indicate Ancient Trans-Atlantic Migration to the Americas? A Critical Re-Evaluation. PaleoAmerica 2015, 1:297-304.

28. Rasmussen M, Sikora M, Albrechtsen A, Korneliussen TS, Moreno-Mayar JV, Poznik GD, Zollikofer CPE, Ponce de Leon MS, Allentoft ME, Moltke I, et al.: The ancestry and affiliations of Kennewick Man. Nature 2015, 523:455-458.

29. Gutenkunst RN, Hernandez RD, Williamson SH, Bustamante CD: Inferring the joint demographic history of multiple populations from multidimensional SNP frequency data. PLoS genetics 2009, 5:e1000695.

30. Schroeder KB, Jakobsson M, Crawford MH, Schurr TG, Boca SM, Conrad DF, Tito RY, Osipova LP, Tarskaia LA, Zhadanov SI, et al.: Haplotypic Background of a Private Allele at High Frequency in the Americas. Molecular Biology and Evolution 2009, 26:995-1016.

31. Ray N, Wegmann D, Fagundes NJR, Wang S, Ruiz-Linares A, Excoffier L: A Statistical Evaluation of Models for the Initial Settlement of the American Continent Emphasizes the Importance of Gene Flow with Asia. Molecular Biology and Evolution 2010, 27:337-345.

32. Lipson M, Loh P-R, Levin A, Reich D, Patterson N, Berger B: Efficient Moment-Based Inference of Admixture Parameters and Sources of Gene Flow. Molecular Biology and Evolution 2013, 30:1788-1802.

33. Schiffels S, Durbin R: Inferring human population size and separation history from multiple genome sequences. Nat Genet 2014, 46:919-925.

34. Raghavan M, Steinrücken M, Harris K, Schiffels S, Rasmussen S, DeGiorgio M, Albrechtsen A, Valdiosera C, Ávila-Arcos MC, Malaspinas A-S: Genomic evidence for the 
35. Raghavan M, Skoglund P, Graf KE, Metspalu M, Albrechtsen A, Moltke I, Rasmussen S, Stafford Jr TW, Orlando L, Metspalu E, et al.: Upper Palaeolithic Siberian genome reveals dual ancestry of Native Americans. Nature 2014, 505:87-91.

36. Skoglund $P$, Mallick S, Bortolini MC, Chennagiri N, Hünemeier T, Petzl-Erler ML, Salzano FM, Patterson N, Reich D: Genetic evidence for two founding populations of the Americas. Nature 2015.

37. Neves W, Pucciarelli $\mathrm{H}$ : The origin of the first Americans-an analysis based on the cranial morphology of early South American human remains. In American Journal of Physical Anthropology: WILEY-LISS DIV JOHN WILEY \& SONS INC 605 THIRD AVE, NEW YORK, NY 10158-0012: 1990:274-274.

38. Neves WA, Prous A, González-José R, Kipnis R, Powell J: Early Holocene human skeletal remains from Santana do Riacho, Brazil: implications for the settlement of the New World. Journal of Human Evolution 2003, 45:19-42.

39. González-José R, Bortolini MC, Santos FR, Bonatto SL: The peopling of America: Craniofacial shape variation on a continental scale and its interpretation from an interdisciplinary view. American Journal of Physical Anthropology 2008, 137:175-187.

40. Fu Q, Posth C, Hajdinjak M, Petr M, Mallick S, Fernandes D, Furtwängler A, Haak W, Meyer M, Mittnik A, et al.: The genetic history of Ice Age Europe. Nature 2016, 534:200-205.

41. Bellwood P: First migrants: ancient migration in global perspective: John Wiley \& Sons; 2014.

42. Rasmussen M, Li Y, Lindgreen S, Pedersen JS, Albrechtsen A, Moltke I, Metspalu M, Metspalu E, Kivisild T, Gupta R, et al.: Ancient human genome sequence of an extinct Palaeo-Eskimo. Nature 2010, 463:757-762.

43. Raghavan M, DeGiorgio M, Albrechtsen A, Moltke I, Skoglund P, Korneliussen TS, Grønnow B, Appelt M, Gulløv HC, Friesen TM, et al.: The genetic prehistory of the New World Arctic. Science 2014, 345.

44. Verdu P, Pemberton TJ, Laurent R, Kemp BM, Gonzalez-Oliver A, Gorodezky C, Hughes CE, Shattuck MR, Petzelt B, Mitchell J, et al.: Patterns of Admixture and Population Structure in Native Populations of Northwest North America. PLoS Genet 2014, 10:e1004530. 

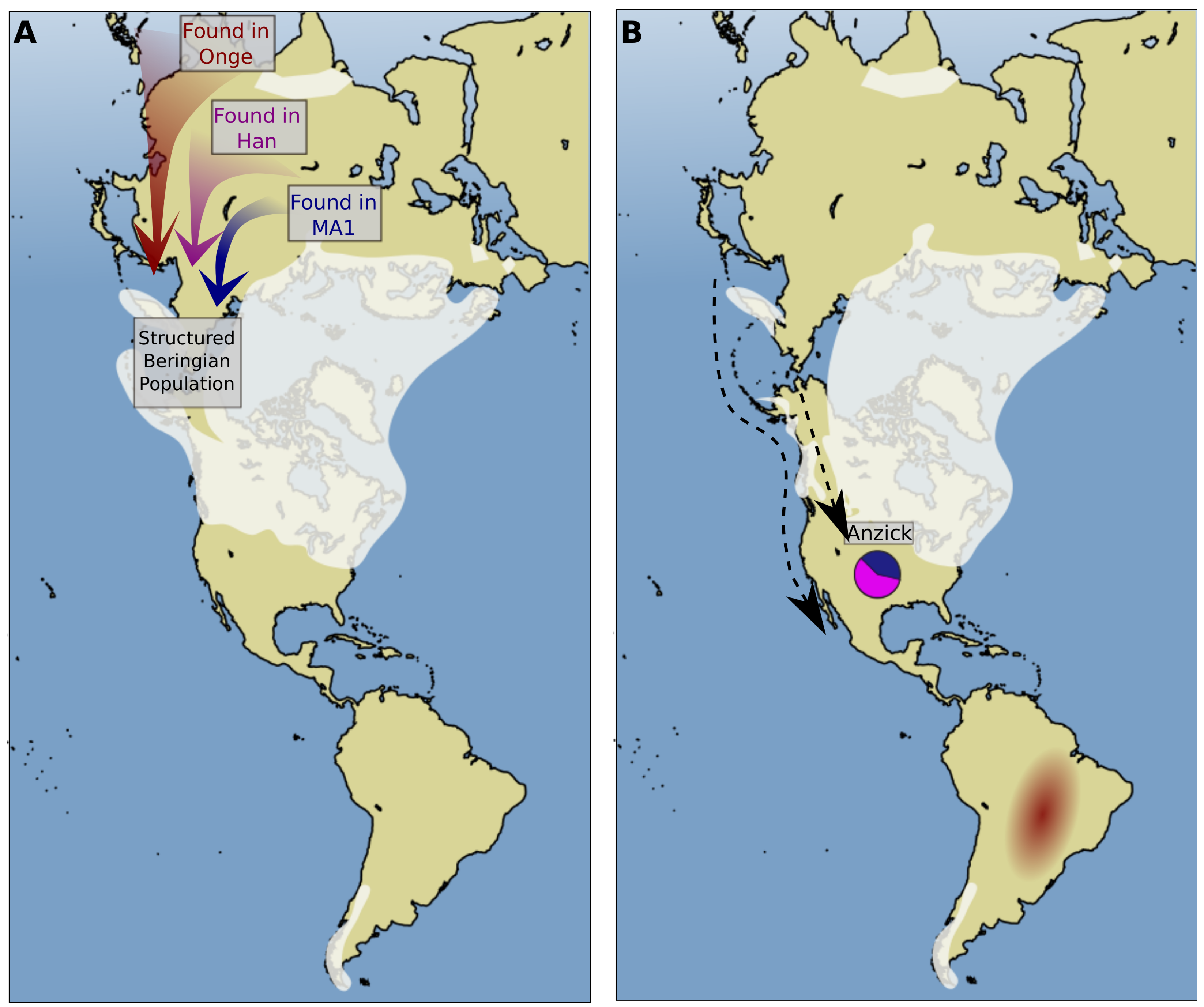
Figure 2

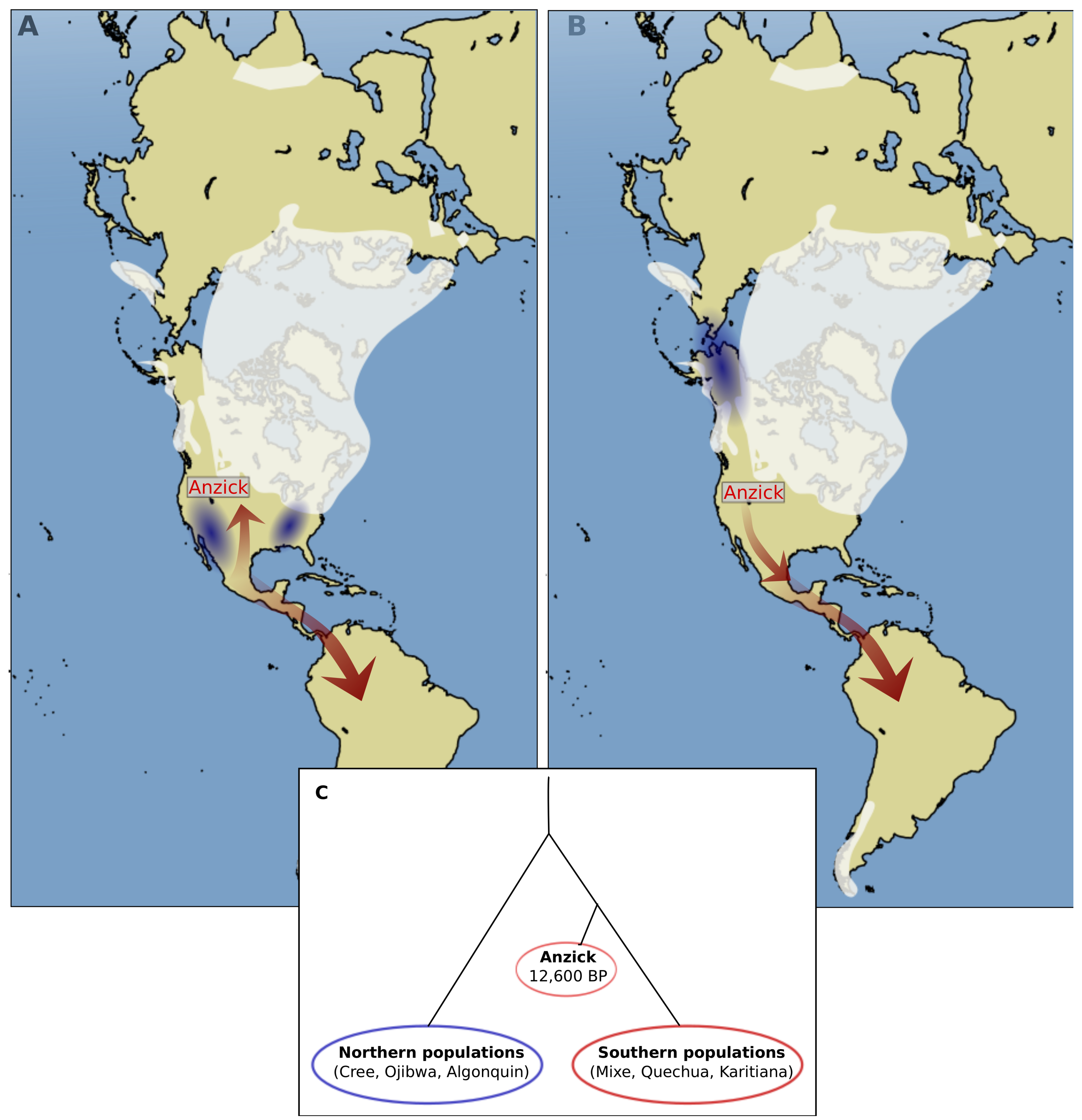


Figure 3

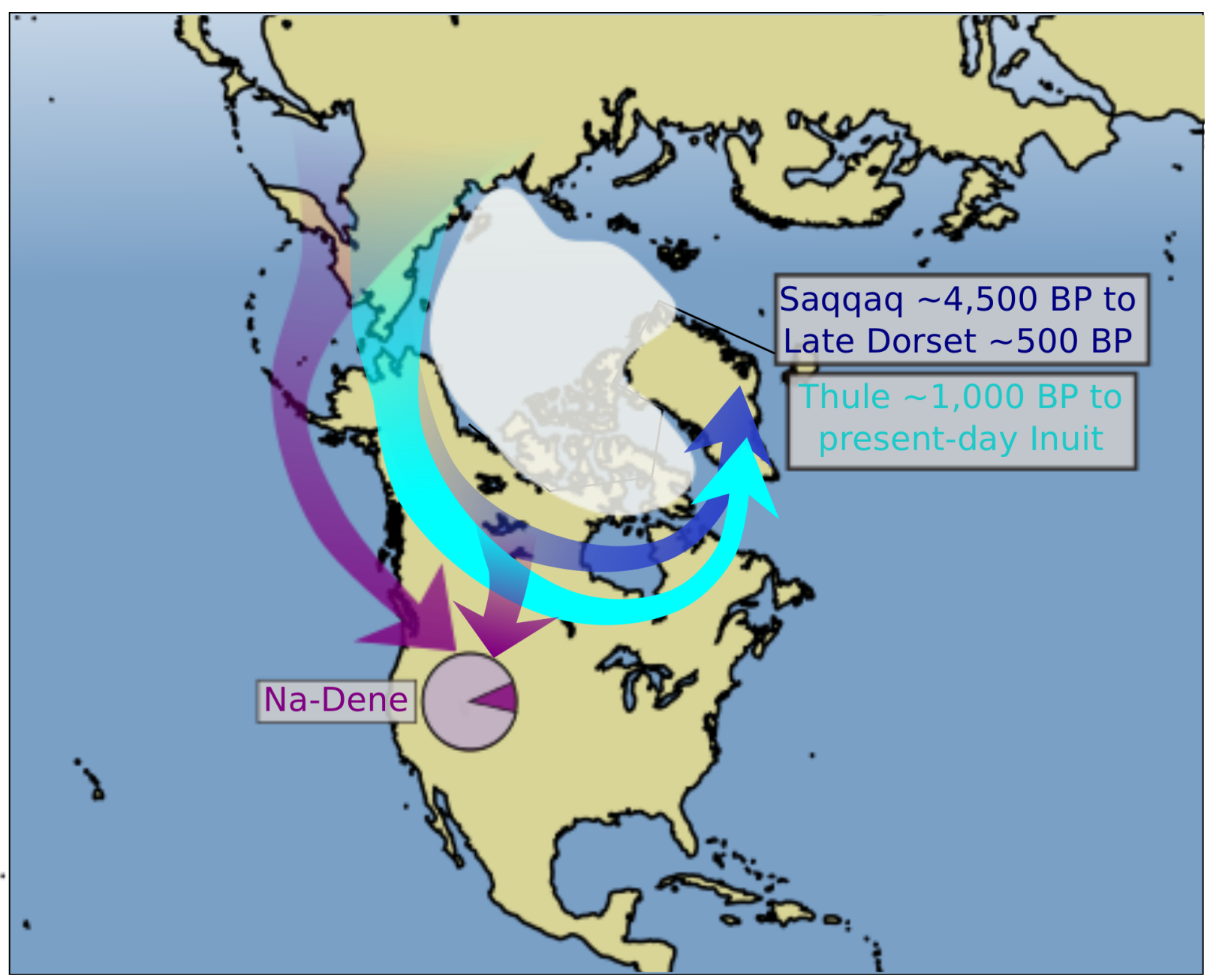

